\title{
Genre analysis of article introductions in economics
}

Igor Lakic

\section{(2) OpenEdition}

1 Journals

\section{Electronic version}

URL: http://journals.openedition.org/asp/3239

DOI: 10.4000/asp.3239

ISSN: 2108-6354

\section{Publisher}

Groupe d'étude et de recherche en anglais de spécialité

\section{Printed version}

Date of publication: 1 December 1997

Number of pages: $409-426$

ISSN: 1246-8185

\section{Electronic reference}

Igor Lakic, "Genre analysis of article introductions in economics », ASp [Online], 15-18 | 1997, Online since 24 November 2012, connection on 21 December 2020. URL : http://journals.openedition.org/ asp/3239 ; DOI : https://doi.org/10.4000/asp.3239

This text was automatically generated on 21 December 2020.

Tous droits réservés 


\title{
Genre analysis of article introductions in economics
}

\author{
Igor Lakic
}

\section{Introduction}

1 Over the last ten years there has been a considerable interest in genre-based analysis of different sorts of texts. This approach derives directly from discourse and text analysis and has been used extensively in the field of English for Specific Purposes (ESP).

2 However, discourse and text analysis cannot provide immediate and direct help in needs analysis, syllabus design and creating materials for ESP courses. Dudley-Evans (1986) claims that text analysis is concerned with the "top down" analysis that tries to establish general features of all texts rather than with the analysis of particular text types or genres. The research in article introductions carried out by John Swales in 1981 created a sort of bridge between the basic postulates of discourse and text analysis on the one hand and the needs of ESP for appropriate syllabuses and materials on the other.

Hyland (1992) claims that genre analysis is "directly relevant to the classroom" by emphasising "the crucial importance of rhetorical text structure". Its research findings have established "common rhetorical patterns... in academic writing" (Dudley-Evans 1993).

4 Applied linguists agree that the author's purpose is of primary importance in creating, a certain genre. However, genre analysis does not look only at the influence of purpose on the choice of grammatical forms, but also takes into consideration rhetorical functions. Robinson (1991) says that the "authors purpose is explained with reference to the wider professional culture to which the author belongs". Thus, genre does not mean only a text-type but also the role of the text in the community within which it has been created. This, in turn, leads to the research of institutional culture.

There have been many attempts to define genre analysis.

5 Dudley-Evans (1987) claims that its principal aim is pedagogical as it provides 
a flexible prescription based on analysis that makes suggestions about the layout, ordering and language appropriate to a particular writing or speaking task

Hopkins and Dudley-Evans (1988) say that the starting assumption of genre analysis is "an explicit description of the way in which texts are organised". Hyland (1992) says that:

genre analysis is the study of how language is used within a particular context. Genres differ in that each has a different goal and they are structured differently to achieve these goals

Bhatia (1991) sees genre analysis as an

analytical framework which reveals not only the utilizable form-function correlations but also contributes significantly to our understanding of the cognitive structuring of information in specific areas of language use, which may help the ESP practitioners to devise appropriate activities potentially significant for the achievement of desired communicative outcomes in specialised academic or occupation areas.

In this sense, genre analysis does not have only pedagogical potential but can also illuminate the process of communication in a given genre. Genre analysis thus combines grammatical insights with corresponding socio-cognitive and cultural explanations. It aims at explaining language in use rather than linguistic forms on the surface level (Bhatia 1993).

The first genre-based analysis was done by John Swales in 1981. He investigated 48 research article (RA) introductions from different fields of science and presented his findings in the work "aspects of Article Introductions", offering a four-move model. Swales claims that article introductions have the structure within which a series of moves (parts) appear in a predictable order. Each move consists of several steps. In 1990, Swales offered a revised model consisting of three moves, urged by some criticisms that it was difficult to differentiate between Move 1 and Move 2. However, it is debatable whether the 3-move model solves this problem. I would argue that the choice between 3-move and 4-move model primarily depends on the discipline in which the genre is applied.

There have been numerous attempts to investigate research article introductions in different scientific fields such as physics, medicine, engineering, biology etc. However, I have not found any attempt of a detailed analysis of RA introductions in economics. The only article regarding this issue is that by Dudley-Evans and Henderson (1990) dealing with the change in economics writing from 1881 to 1980 . They have identified three periods: (1) 1881 to 1925 , (2) 1935 to 1957 and (3) 1961 to 1980, but only a small number of articles was examined (10, 5 and 7 respectively).

10 The introductions from the first period were difficult to identify since they were either not labelled as such and were very short with only a couple of sentences. There is a connection between the title and the introduction in that the introduction explains what is meant by the idea presented in the title, which is usually very short. In two introductions the opening sentence is the statement of the aim of the paper (Move 4 in our analysis). The introductions show that the authors assumed the lack of knowledge on the part of the readers, seeing a need to set the scene for the article.

11 From the second period only one introduction was difficult to identify. The remaining four were labelled. There are examples of some of the moves from the Swales' model (First, Third, Fourth), but the model as a whole cannot still be identified. The titles of papers are more complex than in the previous period. 
12 All the introductions from the third period except one are clearly labelled either by a subtitle or a number. Most of the articles are much longer than in the previous two periods and conform closely to the Swales' model, but there are also some empirical modifications. No definitions or detailed explanations of the existing knowledge are given. The authors point at the part of the problem they want to modify. The 4-move model is supplemented by a guide to the structure of the paper, i.e. to the organisation of the argument in sections.

13 The aim of Dudley-Evans and Henderson was not to establish a model of rhetorical organisation in economics RA introductions, but to show that conventions have changed from the end of the last century till nowadays. That is why they do not offer any model or a detailed description of these introductions.

I therefore decided to do an investigation of RA introductions in economics. I chose 40 introductions from The American Economic Review and 40 from The Economics Journal $(53,340$ words). The purpose of this paper is to present the 4-move model characteristic of economics research article introductions, showing the main characteristics of each move. The results show that economics RA introductions follow Swales' model, but with some differences that are a consequence of some characteristics of economics as a discipline

\section{Method}

Very few attempts have been made to define a corresponding methodology that would be used in the analysis of different genres compared to spoken discourse (Swales, 1990). There is a widespread opinion that the material under investigation imposes a certain methodological approach. I have approached my analysis having in mind Swales' models from 1981 and 1990, taking them only as a starting point.

Identifying the introductions was an easy task since they were all clearly labelled The 80 articles were then carefully read and described. The analysis started from the macrostructure, i.e., from the text as a whole, towards the microstructure or the text components.

The analysis process led to the 4-move model. The moves, except one, consist of steps. Each introduction was divided into moves and steps in accordance with the author's purpose. After that each move and step were subject to a linguistic description (syntactic and lexical). The 4-move model that came out as a result of my analysis is as shown in Table 1.

Table 1: Four-move model

\begin{tabular}{|l|l|}
\hline Move 1 & Establishing the territory \\
\hline Step 1 & Showing Centrality \\
\hline & a. by topic-prominence \\
\hline & b. by interest \\
\hline & c. by importance \\
\hline
\end{tabular}




\begin{tabular}{|l|l|}
\hline & d. by standard-procedure \\
\hline Step 2 & Stating Key Characteristics \\
\hline Step 3 & Stating Current Knowledge \\
\hline Move 2 & Summarising previous research \\
\hline Move 3 & Establishing a niche \\
\hline Step 1 & Indicating a Gap \\
\hline Step 2 & Question-Raising \\
\hline Step 3 & Hypothesis-Raising \\
\hline Step 4 & Questioning Validity \\
\hline Step 5 & Airing a Problem \\
\hline Move 4 & Occupying the niche \\
\hline Step 1 & Describing the Present Research \\
\hline Step 2 & Outlining Purpose \\
\hline Step 3 & Announcing Principal Findings \\
\hline Step 4 & Extending a Finding \\
\hline Step 5 & Indicating RA Structure \\
\hline
\end{tabular}

\section{Analysis}

The analysis showed that the longer the introduction, the more complex the structure of the introductions is, with certain moves repeating cyclically (for example, 1-2-3-4-2-3-4-2-4). The following text is a typical introduction showing the 4-move model. It is also one of the shortest with clearly defined moves.

\section{Keynes's General Theory: Interpreting the Interpretations}

Move 1:

Keynes's General Theory has given rise to a variety of Keynesian research programmes.

Move 2:

The development of these different Keynesian research programmes is well documented (see, for example, Coddington 1976; Gerard 1988; Hamouda and Harcourt 1988, for surveys of Keynesian and post-Keynesian economics).

Move 3:

21 However, less attention has been paid to explaining a striking feature of this Keynesian diversity, namely, the stress placed on discovering the real meaning of Keynes's General 
Theory. The legitimacy of any particular Keynesian research programme has been judged with regard to the authenticity of its implied interpretation of Keynes. Inevitably this concern for authenticity has generated much controversy, enveloping Keynesian economics in a 'doctrinal fog' (Blaug 1980: 221).

Move 4:

This paper attempts to pierce that Keynesian doctrinal fog. The central thesis is that the causes of the controversy surrounding Keynes's General Theory lie, in part, in the different presuppositions made about the nature of interpretation. It is argued that much light can be shed on the Keynesian debate by drawing on the study of hermeneutics.

The structure of the paper is as follows. Section I discusses the atomistic view of interpretation which is implicitly presupposed by most contributors to the Keynesian debate. Two variants of the atomistic view are considered the objectivist/essentialist approach and the relativist approach. Section II provides an alternative presupposition, the organicist view of interpretation, as exemplified by Ricoeur's dialectical approach in hermeneutics. The paper concludes in Section III with a reexamination the Keynesian debate in the light of the organicist view of interpretation (Bill Gerrard, from The Economic Journal 101/405, March 1991).

\section{Move 1 - Establishing the Territory}

Eight introductions out of analysed 80 do not contain Move 1. In most of the remaining 72 introductions, Move 1 appears initially except in 6 instances where it appears after the initial Move 4 or in the middle of the introductions, but again in most cases after Move 4 . It is interesting that all the introductions where Move 1 appears later in the text start with Move 4. In some introductions Move 1 is used cyclically (two or three times in the texts), but all these introductions start with Move 1 as well.

The structure of Move 1 - Showing centrality is the same as in Swales' model. However, the distribution of steps is different than in the articles investigated by Swales. In the article above, the author tries to attract the attention of the audience, first by mentioning Keynes as one of the key figures in the 20th century economic science. By stressing that there is a variety of research programmes on Keynes general theory, the author shows the centrality - topic prominence (Step la) and thus efficiently introduces the topic of his own research. This introduction consists of Step la only, probably due to its shortness. On the other hand, many articles contain more than one step.

Here are some more examples of Step la - Topic prominence from the analysed introductions:

These phenomena have been extensively studied...

The rational-expectations hypothesis plays a central role in...

... increased attention has been paid ..

Step $\mathbf{l b}$ is characterised by the use of the lexeme interest like in the following examples:

In recent years, there has been a marked increase in interest in...

Macroeconomists have always been interested in...

The examples show that this lexeme may appear as both a noun and a verb and the noun is often strengthened by the adjectives such as considerable, growing, etc. 

her own research. Noun importance and adjective important are used in the following examples:

The debates on ... vividly demonstrate the importance of ...

How people form their expectations of future economics events had been an important issue in macroeconomics...

Step ld is the fourth way of showing centrality of a topic. This implies that the author claim the procedure or technique applied in the research to be generally accepted, widespread or standardised. Here are a few examples:

A complete solution is obtained by combining ...

Laboratory economics experiments typically use...

Step 2 - Stating key characteristics is quite frequently used in economics RA introductions (53.77\% out of 72 introductions), which is much more than in Swales' corpus (16.27\%). It is obvious that there is a greater need in economics for presenting key characteristics of a problem. It is probably a consequence of the importance of deriving an economic model that offers a solution to a problem. In Move 4 authors often present their model (either a new one or derived from the already existing ones). In order to do this, Step 1a - Topic Prominence and Step 2 - Stating Key Characteristics are a good starting point. Here the author mainly stresses that there is a particularly significant phenomenon or characteristics of the topic, thus indicating that the subsequent discussion of that phenomenon or characteristic is central, necessary or useful, rather than marginal or gratuitous. In other words, the topic or material under investigation is ascribed a key importance in the paper. This step is also longer that the others and consists of two, three or more sentences, which results from the need to offer a more detailed explanation. Let's have a look at some examples:

Auctions and tenders are fast becoming a key instrument in the allocation of public

franchises and service contracts.

Tax reforms have incorporated a wide verity of proposals.

Step 3 - Stating current knowledge is a part in which the authors want to stress something that is already known about the topic and which is, according to its characteristics, interesting enough to attract the readers' attention. As a rule, the stated characteristic is unusual, controversial or interesting in order to arise the readers' interest. The following examples illustrate this:

It is commonly believed that auctions are most often used when the seller of an object is highly uncertain about the demand for that object.

The policy ineffectiveness proposition of the New Classical school states that...

\section{Move 2 - Summarising Previous Research}

In economics RA introductions this part has an important part. By referring to previous work, the author both establishes a solid theoretical basis for his own research and tries, although somewhat less than in Step 1, to attract the attention of readers Besides, by offering account of previous work and stating the views of others on a certain problem, the author opens a good way towards Move 3 and Move 4 that more or less rely on Move 2 .

Dudley-Evans (1986) says that many authors criticised Swales' model because it was impossible to draw a clear line between Move 1 and Move 2. Having this in mind, Swales 
offered a revised three-move model in which «Reviewing items of previous research" appears as Step 3 in Move 1.

However, my analysis has shown that it is justifiable to separate Move 1 and Move 2, at least from the economics point of view. I have found a confirmation of this in Bhatia (1993) who says that although it may be difficult to separate these two moves, "there are equally strong and perhaps more valid, arguments in favour of assigning a separate status to move 2». This part is a very important foundation for further work in economics RA. Authors do not refer to previous work just because it is a convention, but because they need the work to support their own research and conclusions. The fact that this part is not so important in electronics, for example, is more a result of the fact that new achievements in electronics are very frequent and are often not based on any previous work. Besides, I did not have problems in differentiating this move, although sometimes it is embedded in one of the other three moves.

In some cases Move 2 was not simply embedded in another move but was rather combined with Move 3, such as in the following example:

However, relatively few American economists since 1940s and 1950s (Richard A.

Lester 1948; Lloyd G. Reynolds 1951) have investigated ..

If we know that Move 2 offers a review of previous literature and Move 3 often points at a gap in the existing knowledge, the problem of separating these two moves becomes obvious. However, the number of such examples is small (four sentences), so this phenomenon cannot be taken as a rule.

Another possibility is a combination of Move 2 with Move 3:

In the past ten years, several econometric studies of intra-industry trade have examined... cf. Balassa and Bauwens (1987).

Swales does not mention these possibilities in his books (1981 and 1990).

There are 519 references in my corpus. The average number of references in the analysed papers is 6.48 .

Swales (1990) makes a distinction between integral and non-integral citation. Jacoby (1987) also suggests summary review where names of authors are not mentioned but "where clear reference to the state of previous research... can be identified" (Jacoby, 1987). Swales claims that Summary does not fall into the category of citation and assigns it to Step la (Topic prominence). Here is an example:

Generative grammarians have recently modified their position.

42 I believe that Jacoby's attitude is more acceptable. Namely, although there is some formal similarity with Step la, the function of these sentences is not the same. Besides, the position of these sentences within the introduction is such that they can hardly be regarded as a part of Move 1 without breaking the text cohesion. This has led me to include "Summary review" in this Move as a third way of citation.

3 However, there are no steps in this move. There are only three ways of reviewing items of previous knowledge. These are: Integral citation, Non-integral citation, Summary review.

In Integral citation, names of authors may appear as a) subject, b) object of a passive sentence, c) a part of an adverbial modifier or d) a part of a postmodifier. Here are four examples for the four ways of integral citation:

(a) Takacs (1987) points out that...

(b) The difficulties...have been forcefully pointed out b Richard Roll (1977).

(c) For example, in Stiglitz and Weiss (1988)... the moral hazards... 
(d) For example, the studies by Epple and Hansem (1981)...

In some cases the authors cite their own previous work, such as in

Our earlier paper focuses on...

but they mainly avoid to mention the title of the paper. By doing this they avoid to attribute too much significance to their contribution to the existing knowledge which may be considered a sort of "modesty" or "hedging".

In Non-integral citation there are two possibilities: authors are mentioned in either parentheses or footnotes. An example for the former is the following:

It formed the basis of ... (T. J. Sargent and Heil Wallace, 1981)

48 The article above contains this kind of citation, mainly encountered in The American Economic Review, even where this part could fit quite well into the main text as an integral citation.

I have already explained the reasons for including Summary review in this Move. This part mainly consists of one sentence such as:

Previous research has analysed...

Some recent papers attempt to explain...

alysis of the use of verb tenses in Move 2 was an interesting part of the research since the use of tenses partly reveals the author's stance towards the cited work. Shaw (1992) quotes the results of Oster (1981) who found that: a) Present Perfect is used when the author wants to continue discussion based on previous literature or to point out that previous results are generally accepted; b) Past Simple is used when previous results are not generally accepted and therefore do not support author's claims; c) Present Simple is used when previous results support author's claims or when he wants to mention previous results without discussing their validity.

51 In the analysed corpus, out of 200 verbs, 55\% (88 cases of active voice and 21 of passive) are in Present Simple Tense. Past Simple Tense appears in $14.5 \%$ of all cases (24 in active and 5 in passive). Present Perfect Tense can be found in 30.5\% (61 examples, 36 in active and 25 in passive). These results are different from those of Swales (1990) in biology and medicine RA and those of Shaw (1992) in agricultural biology and biochemistry doctoral theses, as can be seen from the chart in Table 2.

Table 2

\begin{tabular}{|l|l|l|l|}
\hline Tense & Swales & Shaw & My result \\
\hline Present Simple & $2.38 \%$ & $17.58 \%$ & $55 \%$ \\
\hline Past Simple & $78.57 \%$ & $51.05 \%$ & $14.5 \%$ \\
\hline Present Perfect & $19.5 \%$ & $31.39 \%$ & $30.5 \%$ \\
\hline
\end{tabular}

52 My results show that economics authors tend to cite research that supports their own work. In economics where a lot of things are explained by means of models, this is quite predictable and justifies the use of Present Simple. The use of Present Perfect is in accordance with this. Namely, the authors of economics RA do not only accept results of other authors but put forth their own models on which economics as a field of science is 
based. A small occurrence of verbs in Past Simple is therefore understandable. Since introductions in economics RA are quite long, it can be supposed that the authors avoid to mention authors whose research does not contribute to their own work. More frequent use of Past Simple in engineering or science can be explained by the fact that new discoveries in this field' are frequent (for example, computers) and often deny or do not rely on any previous results which are not valid any more and do not have general significance. Economics facts, on the other hand, are generally accepted and new knowledge is built upon them. In that sense, research of other authors is only a step in the pyramid of economics knowledge. That is why the use of Present Simple and Present Perfect is both justifiable and predictable.

\section{Move 3 - Establishing a Niche}

After giving a review of literature, the author needs to offer a sort of an evaluation of it. This evaluation, which usually disputes previous results, shows the purpose of Move 2. At the beginning of the paper, particularly in Move 2, the author is fully detached from the discussion because work of other authors is cited. Now, the author enters the discussion as a connoisseur of the problem.

found no traces of Move 3 in 8 papers out of 80. In 4 other papers Move 3 is embedded into other moves. There are also three papers where Move 3 is initial. The structure of Move 3 is somewhat different from Swales' model. Thus, I have found no examples of what Swales labelled "Continuing tradition" and there are only three cases of "Counter-claiming". On the other hand, there is a difference in the number of steps in my analysis, because in Swales' corpus some of these steps exist only as sub-steps. These steps were established in accordance with their function in the text and there are five of them.

Another problem is that in Swales' analysis the use of one step excludes the use of other steps in this Move. It is probably because Swales analysed only short introductions. The introductions from my corpus are longer and the analysis shows that the same introduction may contain more than one step.

Step 1 - Indicating a gap is characterised by the use of conjunctions however, but, yet. Different lexical means are used to express the gap in the existing knowledge.

A. The first possibility is lexical negation, i.e., adjective. verb, noun or adverb that are the exponents of the negation. Here are examples for each of them:

It can lead to false rejection of rational expectations ...

...many tests fall to...

...there exist valid doubts concerning...

Summary statistics... rarely reveal...

B. Authors may also use negative or quasi-negative quantifiers (i.e. indefinite adjectives or pronouns) such as in the following examples:

there is relatively little evidence...

No serious explanation is given...

None of these studies considers channel issues.

There are few economic studies

C. The third possibility is negation within verb phrase:

However, in those papers the authors do not examine directly... 
D. There are also four interesting examples that fall into the group of "contrastive comment" where the authors point at a gap by mentioning what other researchers have done instead of doing something different. They do it in the following way:

First, some use average survey response data rather than individual data.

61 E. Finally, there are examples showing that the author supposes or believes on the basis of previous research, that a different conclusion may be drawn from what the other authors state as a conclusion ("logical conclusion»). In that way, the author, although less directly, stresses a gap in previous knowledge, mainly using modal verbs such as may or might. Here is one example:

...there must be some plans which might (or might not) be considered...

62 Step 2 - Question raising is another way of establishing the niche. The author puts forward the questions that previous research did not answer. This is quite an efficient way of preparing terrain for Move 4 . The questions that the author raises may be both direct and indirect. Noun question is frequently used in sentences containing indirect question.

... the relevant question is whether they are likely to result in...

63 Step 3 - Hypothesis raising contains examples in which the author sets forth his hypotheses for what should be done, studied, analysed, considered or provided in order to examine the problem fully. Let's have a look at one example:

It seems useful to generalize the previous approach to this more general case.

Step 4 - Questioning validity is a part where the author does not express his negative attitude towards previous research directly, but just leaves a possibility that previous research may have some disadvantages. Language means are therefore less direct (conditionals are used quite often).

If confirmed, this finding would imply that many other forces have been relatively unimportant.

Step 5 - Airing a problem is used when the author wants to point out a problem, thus making ground for explaining in Move 4 that his paper aims at solving the problem. Different language means are used here, depending on the problem under investigation. The only noticeable characteristic is an occasional occurrence of the noun problem.

Yet, the weight of academic how-and-economics commentary has been opposed to

the regulation of insider trading

ving all this in mind, we can conclude that Move 3 in the cited text starts with Step 1 Indicating a gap. Sentence modifier however and indefinite quantifier less confirm this conclusion. In the next two sentences the author further explains his attitude.

Although many believe that Move 3 is only a transient move, its function is much more important and complex. In most cases introductions would sound incomplete without this move. The absence of Move 3 also changes the character of Move 4. In this case, the author does not try to fill the gap or answer a question. Instead, by taking Move 2 as a starting point, he states his intention to extend the previous models or analyses, without denying their results.

\section{Move 4 - Occupying the Niche}

In this move, the author is expected to offer a way to cross the gap mentioned in the previous move, answer the question(s) or respond in a way to a problem put forth in 
Move 3. Authors sometimes state their results in the introduction. This is a way of attracting the readers' attention. On the other hand, they can leave it for the end of the paper, thus maintaining suspense (Swales 1981). From our corpus it turns out that most American authors (34 out of 40) state their results in the introduction and 6 avoid doing so. On the other hand, only half of the authors in the Economic Journal indicate their results in the introduction. Of course, the introduction does not offer all the results but only a part that might appeal to the members of the discourse community.

Another characteristic of economics texts needs to be mentioned here. Compared to chemists or biologists, for example, who can do controlled experiments, economists tend to move between "the real world and a hypothetical or idealised world" (Hewings 1990). This means that they can only observe and predict. The factors influencing a certain economic phenomenon vary from one situation to another which makes the economists use models. "Assumptions" are the basis of forming economic models that replace experiments in the physical sciences. Models are also tested in idealised world where all the influences can be controlled. It is only then that the results obtained are used in real situations. This explains the fact that most of the analysed articles are based on presenting a new model or extending a previous one. The noun model, although not mentioned many times in the texts, is an underlying word of economics and is also a basis of Move 4.

Due to its function, this move is rather complex. Lexical means helping to recognise its occurrence appear at the very beginning. This move may appear in the initial, middle or final position in the text, but is mostly encountered In the final position.

The order and the number of steps is different in my model from the Swales model. Here is the structure of Move 4:

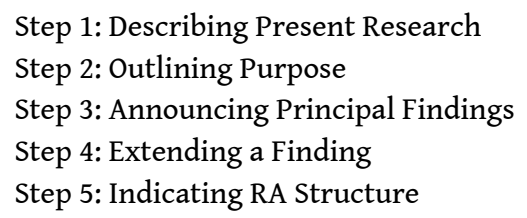

Step 1 - Describing present research is very important because it is only now that readers become familiar with the basic attitudes and claims of the author. A The most frequent signal in this step in the phrase In this paper... followed by first person pronouns we or I. Sometimes, passive voice is used instead of pronouns. Here are two examples:

In this paper, I examine...

In this paper a model... is proposed

B. Another frequent signal is this/the followed mainly by the noun paper, but also by study, analysis and model:

This paper studies...

The paper investigates...

C. The next signals are the first person pronouns I or we. In previous examples these two pronouns are also used but not as a key signal.

We estimate alternative versions

I develop a two-stage model...

76 It is worth mentioning that the verb attempt appears from time to time, showing that the authors use "hedging" as a sign of modesty, as in the following example:

We attempt to... 

small number of cases. By avoiding the use of $I$ or we, they stress the importance of the research itself, not their contribution to it.

The original and revised models are examined for adequacy by...

E. The last group in this step is specific because the authors explain the procedure of their research. In physical science articles, this group would probably fall into a separate step. Since it appears rather infrequently in economics introductions, I have decided to incorporate it into this step. This makes sense since these examples are also a description of the present research.

We use a large panel data...

Data are drawn from...

The verbs used in this step are (in order of frequency): use, develop, examine, estimate, provide, investigate, focus, derive, consider, assume, discuss, analyse, study, concentrate, point out, test, explain...

Step 2 - Outlining Purpose. This is less frequent than in the analysis carried out by Swales. Besides, Swales puts this step together with the "Description of the present research". I have decided to separate them into two steps because, although they have some characteristics in common, these two steps have different functions in the text.

The key signal in this step is "The purpose of this paper..." as in:

The purpose of this paper is to examine...

Instead of purpose the following nouns also appear: objective, object, goal and aim.

The verbs used are: examine, establish, estimate, extend, re-evaluate, further, use, consider, argue, present, identify, demonstrate, show, generalise, offer, reformulate, document, provide, isolate, remedy and describe.

Step 3 - Announcing principal findings. As I have already discussed presenting results in the introductory sections, I shall simply give some examples of this step.

\section{A. The most frequent construction is}

The paper shows that...

but the following variations, among others, may be found:

The evidence suggests...

The results clearly provide...

The findings provide...

B. In this step the authors also use first person pronouns, as in the following examples:

We show that...

I find that...

C. The next group are sentences where the subject is a noun phrase with the noun result as a centre, usually followed by the verb to be.

The key result of this paper is that...

D. passive is also a possibility:

It is shown that...

...cooperation is shown to be possible

E. In a number of cases the results are stated directly, without any special signals or with the signals different from those mentioned above. When taken out of context, some of these examples may look difficult to classify. However, a careful reading clarifies that these are results of the analysis carried out by authors. Here is one example: 
Thus, ... in our setting an increase in population may reduce the extent

F. There is also a group of examples where the authors indicate the contribution of their research to the existing knowledge. The following examples illustrate this use:

This paper contributes to our understanding...

This paper may be viewed as a contribution to the large literature in learning about...

Step 4 - Extending a finding is usually found in introductions without Move 3, that is where the authors do not find a gap to cross or a question to be answered, but just extend the previous models or knowledge. This explains the use of the verb extend and the noun extension in some examples. Let us look at a couple of examples:

Our analysis extends the work of...

This paper extends...

Step 5 - Indicating RA structure, just hinted at by Swales, seems to take up a very important place in the economics RA introductions. Only 11 introductions out of 80 do not contain this step.

In 34 introductions this step starts with an introductory sentence, the most frequent being the following one:

The paper is organised as follows...

The following sentences mainly explain the content of each section of the paper as in the following examples:

Section III discusses...

Section II presents...

First person pronouns are also used here:

In section II, we serve...

In Section IV I study...

There are 58 different verbs used in examples like these and numerous variations and extensions of these sentences can be found throughout the corpus. There is also a group of sentences occurring at the very end, which draw readers' attention to the concluding section. Here is an example:

Section V summarises...

Section V concludes...

Although this step has some common characteristics with Step 1- Describing the present research, its principal function is different and it is for this reason that it is classified as a separate step.

In the text quoted on page 5, Move 4 starts quite clearly. The author, using the verb attempt stresses the aim of his work (Step 2) in order to cross the gap. The noun phrase "The central thesis..." introduces Step 3 (Announcing principal findings). The next sentence starting with "It is argued that..." can also be classified into Step 3. The last passage is an example of Step 5 (Indicating RA structure), which shows that economics authors pay a lot of attention to this part of their introductions.

\section{Conclusion}

100 The investigation of economics RA introductions proves the justifiability of Swales' model in analysing different genres. It also shows that the model does not offer prepared solutions but helps a lot in the analysis of different text types. Familiarisation with the 
model of John Swales helped me to analyse the texts and construct a model that reflects the rhetorical structure of economics RA introductions.

\section{BIBLIOGRAPHY}

Bhatia, V. 1991. "A genre-based approach to ESP materials". World Englishes 10/2, 153-166.

Bhatia, V. 1993. Analysing Genre: Language Use in Professional Settings. London: Longman.

Dudley-Evans, T. 1986. "Genre analysis: an investigation of the introduction and discussion sections of MSc dissertations". In Coulthard M. (ed.), Talking about Text, Discourse Analysis Monograph No. 13, Birmingham: English Language Research, University of Birmingham, 128-145. Dudley-Evans, A. 1987. “Introduction to genre analysis and ESP”. ELR Journal l.

Dudley-Evans, A. and W. Henderson. 1990. "The organization of article introductions: evidence of change in economics writing". In Dudley-Evans, T. and W. Henderson (eds.), The Language of 
Economics: The Analysis of Economics Discourse, ELT Documents: 134, London: Modem English Publications in association with the British Council.

Dudley-Evans, T. 1993. "Variation in communication patterns between discourse communities: the case of highway engineering and plant biology". In Blue, G. M. (ed.), Language Learning and Success: Studying Through English, vol. 3/1, London: Modem English Publications in association with the British Council.

Hewings, M. "Aspects of the language of economics textbooks". In Dudley-Evans, T. and W. Henderson (eds.), The Language of Economics: The Analysis of Economics Discourse, ELT Documents: 134, London: Modern English Publications in association with the British Council.

Hopkins, A. and T. Dudley-Evans. 1988. "A genre-based investigation of the discussions sections in articles and dissertation". English for Specific Purposes 7/2, 113-122.

Hyland, K. 1992. “Genre analysis: just another fad?”. Forum 30/2, 1-17.

Jacoby, S. 1987. "References to other researchers in literary research articles". In Dudley-Evans, T. (ed.), Genre Analysis and ESP. Birmingham: University of Birmingham.

Oster, S. 1981. “The use of tenses in 'Reporting past literature' in ESP”. In Selinker, L., E. Tarone and V. Hazeli (eds.), English for Academic and Technical Purposes: Studies in Honor of Louis Trimble. Rowley, MA: Newbury House, 76-90.

Robinson, P. 1991. ESP Today: A Practitioner's Guide. Hemel Hempstead: Prentice Hall.

Shaw, P. 1992. "Reasons for correlation of voice, tense and sentence function in reporting verbs". Applied Linguistics 13/3, 301-319.

Swales, J. 1981. Aspects of Article Introductions. Aston ESP Research Report No. 1. Language Studies Unit. University of Aston in Birmingham.

Swales, J. 1990. Genre Analysis. English in Academic and Research Settings. Cambridge: Cambridge University Press.

\section{ABSTRACTS}

Genre analysis is a new approach to discourse and text analysis in ESP. Its research findings have established common rhetorical patterns in academic writing. Therefore genre analysis has an important role in developing both writing and reading skills. This paper gives basic postulates of genre analysis and offers the predominating four-move model in economics research articles from the analysis of 80 introductions. The paper then briefly discusses some pedagogical implications of genre analysis.

L'analyse de genre est une nouvelle approche de l'analyse du discours et du texte en anglais de spécialité. Il est maintenant établi qu'il existe des modèles rhétoriques communs de l'expression écrite en langue spécialisée. C'est pourquoi l'analyse de genre joue un rôle important dans le développement des compétences de lecture et d'écriture. À partir des principes de base de l'analyse de genre énoncés ici et en nous référant à l'analyse de 80 introductions d'articles de recherche en économie, nous en présentons le modèle à quatre temps. Nous évoquons ensuite brièvement quelques répercussions de l'analyse de genre dans le domaine pédagogique. 
INDEX

Keywords: article introduction, discourse analysis, four-move model, genre analysis

Mots-clés: analyse du discours, analyse de genre, introduction d'article, modèle à quatre étapes

\section{AUTHOR}

\section{IGOR LAKIC}

Igor Lakic teaches at the Institute for Foreign Languages, University of Montenegro. 